\title{
Aerodynamic Analysis of Curved Blade for Water Pumping Windmill
}

\author{
Khaing Zaw Lin \\ Department of Mechanical \\ Engineering, \\ Technological University \\ Thanlyin, Myanmar
}

\author{
Thwe Thwe Htay \\ Department of Mechanical \\ Engineering, \\ Technological University \\ Thanlyin, Myanmar
}

\author{
Su Yin Win \\ Department of Mechanical \\ Engineering, \\ Technological University \\ Thanlyin, Myanmar
}

\begin{abstract}
Design of a rotor of a windmill is very important to extract the energy from the wind. The design of rotor involves the calculation the rotor parameters and its components to produce maximum power. Although the design of a wind mill looks simple, it involves complex and detailed design of its components like rotor, transmission, load matching, yawing mechanism etc. In this paper, aerodynamic analysis of a curved blade for windmill is simulated by comparing NACA standard airfoils. Two-dimensional numerical modelling of the airfoil of the windmill is performed with COMSOL Multiphysics software. The velocity and pressure distribution around airfoil can be checked from the simulation results. The 2D airfoil geometry is realized in COMSOL's geometry tools. Two dimension and steady state model has been used and boundary conditions are considered within computations as the flow in wind tunnel.
\end{abstract}

Keywords: windmill, curved blade, CFD, velocity field, pressure distribution

\section{INTRODUCTION}

Today, wind pumps are used in many places all over the world because wind energy is a good alternative power source for water pumping. In this system horizontal axis multi-blade windmill is considered and pinions and gears will be used for power transmission. A reciprocating pump will be used to operate at low speed. This system consists of three main parts, which are a wind mill, a transmission system and a single acting reciprocating pump. Available wind energy can be received by wind blades from a windmill and then takes out the mechanical energy via the crank arm to the reciprocating pump.

\section{WINDMILL}

The use of mechanical equipment to convert wind energy to pump water goes back many years. Windmills are classified as vertical or horizontal axis machines depending on the axis of rotation of the rotor. Vertical axis windmills can obtain power from all wind directions whereas horizontal axis windmills must be able to rotate into the wind to extract power. Windmills are also classified as either electrical power generators or water pumpers. Power generators typically operate at high rotational speeds with low starting torques. Direct water pumping windmills are characterized by a multiblade, horizontal axis design set over top of the well as shown in Fig.1. Water pumping requires a high torque to start the pump and it can get by using the multi-blade design. [1]

\section{NUMERICAL SIMULATION}

The rapid evolution of computational fluid dynamics (CFD) has been driven by the need for faster and more accurate methods for the calculations of flow fields around configurations of technical interest. In the past decade, CFD was the method of choice in the design of many aerospace, automotive and industrial components and processes in which fluid or gas flows play a major role. In the fluid dynamics, there are many commercial CFD packages available for modeling flow in or around objects. The computer simulations show features and details that are difficult, expensive or impossible to measure or visualize experimentally. For this reasons, the researchers and students are more concerned with the computer simulations. [2]

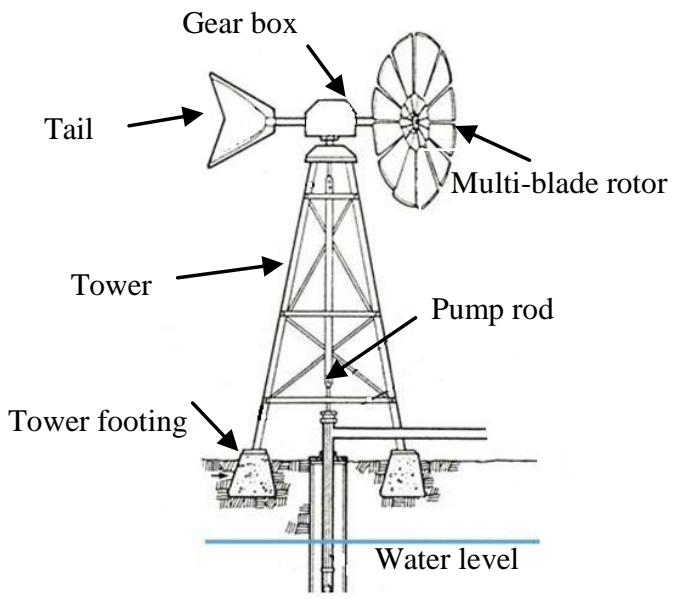

Figure. 1 Components of windmill for water pumping system [2]

Traditionally, drag and lift coefficients of an object can be measured with tests in a wind tunnel. Due to the decrease in the cost of computations compared to the increase in the cost of experiment, computational fluid dynamics is replacing the wind tunnel tests. With development of efficient and cost effective CFD software, CFD plays a pivotal role in academic and industrial research for preliminary result in design of new products. The numerical simulations are performed with COMSOL Multiphysics $4.3 \mathrm{~b}$, a finite element method based software. The COMSOL Multiphysics is a commercial partial differential equation solver that enables simultaneous computation of multiple physics. The advantage of COMSOL Multiphysics includes its user friendly modeling interface, versatility of physical models, and its accuracy.

The simulation process includes modeling of the geometry of the model, meshing the geometry created into elements to approximate the solution easily using simple functions, 
defining material properties. Boundary, initial and loading conditions must also be specified which require experience, knowledge and engineering judgment. Finally, the solution is obtained by solving the simultaneous equations for the field variables at the nodes of the mesh. [3]

\section{CFD MODULE}

The CFD Module is an optional package that extends the COMSOL Multiphysics modeling environment with customized user interfaces and functionality optimized for the analysis of all types of fluid flow. The CFD Module is used by engineers and scientists to understand, predict, and design the flow in closed and open systems. At a given cost, these CFD simulations typically yield new and better products and operation of devices and processes compared to purely empirical studies involving fluid flow. As a part of an investigation, simulations give accurate estimates of flow patterns, pressure losses, forces on surfaces subjected to a flow, temperature distribution, and variations in fluid composition in a system.

The CFD Module's general capabilities include stationary and time-dependent flows in two-dimensional and threedimensional spaces. Formulations of different types of flow are predefined in a number of fluid flow user interfaces to set up and solve fluid flow problems. The fluid flow user interfaces define a fluid flow problem using physical quantities, such as pressure and flow rate, and physical properties, such as viscosity. There are different fluid flow user interfaces that cover a wide range of flows such as laminar flow, turbulent flow, single-phase flow, and multiphase flow. In this thesis, single-phase flow at stationary in two-dimensional space is considered. [3]

The fluid flow user interfaces formulate conservation laws for the momentum, mass, and energy. These laws are expressed in partial differential equations, which are solved by the module together with the corresponding initial conditions and boundary conditions. The equations are solved using stabilized finite element formulations for fluid flow, in combination with damped Newton methods and, for timedependent problems, different time-dependent solver algorithms. The results are presented in the graphic window and derived tabulated quantities obtained from a simulation. The work flow can be described by the following steps: define the geometry, select the fluid, select the type of flow, define boundary and initial conditions, define the finite element mesh, select a solver, and visualize the results. [4]

\subsection{Single Phase Flow}

The single-phase flow branch included with the CFD Module has a number of subbranches with physics interfaces that describe different types of single-phase fluid flow. They are laminar flow, turbulent flow, creeping flow and rotating machinery fluid flow. The Laminar Flow user interface is primarily applied flows of low to intermediate Reynolds numbers. The user interface solves the Navier-Stokes equations, for incompressible and weakly compressible flows (up to Mach 0.3). This fluid flow user interface also allows for simulation of non-Newtonian fluid flow.

The user interfaces under the turbulent flow branch model flow of high Reynolds numbers. These user interfaces solve the Reynolds-averaged Navier-Stokes (RANS) equations for the averaged velocity field and averaged pressure. The turbulent flow user interfaces have different models for the turbulent viscosity. There are several turbulence models such as a standard $k-\varepsilon$ model, a $k-\omega$ model, an SST (Shear Stress Transport) model, a Low Reynolds number $k-\varepsilon$ model and the Spalart-Allmaras model. The SST model combines the robustness of the $k-\varepsilon$ model with the accuracy of the $k-\omega$ model, making it applicable to a wide variety of turbulent flows.

The creeping flow user interface approximates the NavierStokes equations for very low Reynolds numbers. This is often referred to as Stokes flow and is appropriate for use when viscous flow is dominant, such as in very small channels or micro fluidics applications. The physics user interfaces support compressibility (Mach < 0.3), laminar nonNewtonian flow, and turbulent flow using the standard $k-\varepsilon$ model.

In this case, turbulent flow SST model is considered for the simulation of curved blade airfoil. The turbulent flow SST user interface has the equations, boundary conditions, and volume forces for modeling turbulent flow using the SST turbulence model. The main feature is fluid properties, which adds the Navier-Stokes equations and the transport equations for the turbulent kinetic energy $(k)$ and the specific dissipation $(\omega)$, and provides an interface for defining the fluid material and its properties. Turbulence model parameters are optimized to fit as many flow types as possible, but better performance can be obtained by tuning the model parameters. The dependent variables such as velocity field, pressure, turbulent kinetic energy, specific dissipation rate and reciprocal wall distance must be defined for the simulation model. [5]

\subsection{Theory of Lift and Drag in Turbulence Modeling}

Turbulence is a property of the flow field and it is mainly characterized by a wide range of flow scales. The tendency for an isothermal flow to become turbulent is measured by the Reynolds number,

$$
\mathrm{R}_{\mathrm{e}}=\frac{\rho \mathrm{UL}}{\mu}
$$

where $\mu$ is the dynamic viscosity, $\rho$ is the density, and $U$ and $\mathrm{L}$ are velocity and length scales of the flow, respectively. Flows with high Reynolds numbers tend to become turbulent and this is the case for most engineering applications. The Navier-Stokes equation can be used as a governing equation for turbulent flow simulations, although this would require a large number of elements to capture the wide range of scales in the flow. These equations are applicable for incompressible as well as compressible flows where the density varies.

$$
\begin{aligned}
\rho \frac{\partial \mathrm{u}}{\partial \mathrm{t}}+\rho(\mathrm{u} . \nabla) \mathrm{u}=\nabla \cdot[-\mathrm{pI}+\mu(\nabla \mathrm{u}+(\nabla \mathrm{u}) \mathrm{T}]+\mathrm{F} \\
\begin{aligned}
\rho \nabla \cdot \mathrm{u} & =0 \\
\rho & - \text { the density, } \mathrm{kg} / \mathrm{m}^{3} \\
\mathrm{u} & - \text { the velocity vector, } \mathrm{m} / \mathrm{s} \\
\mathrm{p} & - \text { pressure, } \mathrm{Pa} \\
\mu & - \text { dynamic viscosity, Pa.s } \\
\mathrm{T} & - \text { the absolute temperature, } \mathrm{K} \\
\mathrm{F} & - \text { the volume force vector, } \mathrm{N} / \mathrm{m}^{3}
\end{aligned}
\end{aligned}
$$

Any solid object of any shape, when subjected to a fluid stream, will experience a force Ftot from the flow. The sources of this force are shear stresses (viscous effects) and normal stresses (pressure effects) on the surface of the object. For an airfoil, distribution of pressure and shear stress on its surface area, A is schematically shown in Figure 2. The negative pressures in the pressure distribution sketch means negative with respect to atmospheric pressure (negative gage pressure). The total force on the airfoil is the summation of pressure and viscous forces. 


$$
\mathrm{F}_{\mathrm{tot}}=\int_{\mathrm{A}} \mathrm{pdA}+\int_{\mathrm{A}} \tau_{\mathrm{W}} \mathrm{dA}
$$

This total force can be divided into two components: lift force which is normal to the free stream velocity, and drag force which is parallel to the free stream.

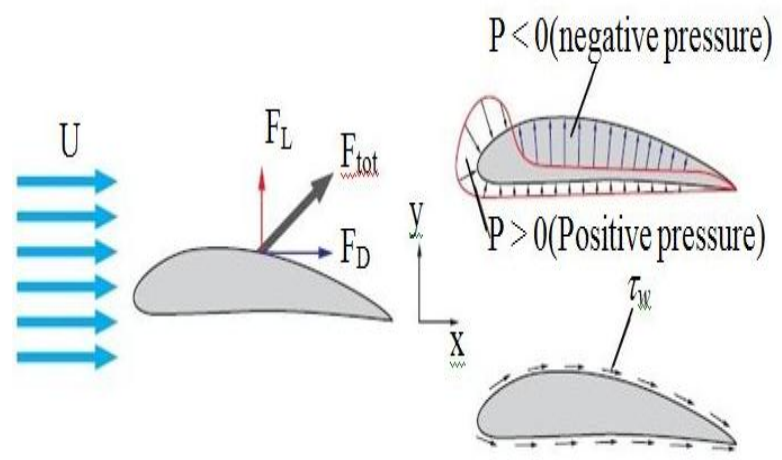

Figure 2. Pressure Distribution around an Airfoil [3]

Let's consider a small elemental area on an airfoil as shown in Figure 3. Components of the fluid forces in $x$ and $y$ directions can be determined.

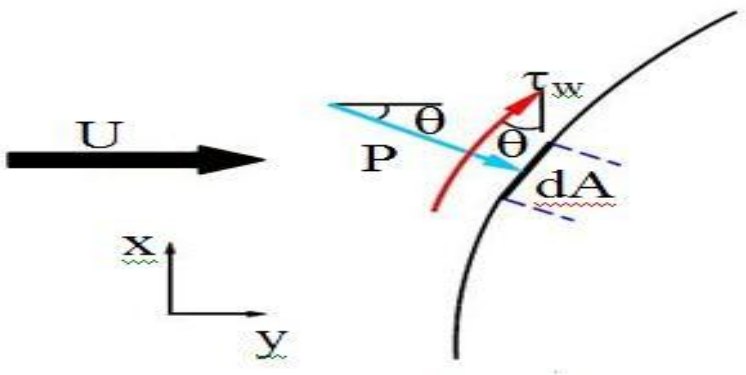

\section{Airfoil surface}

Figure 3. Normal Stress and Shear Stress on Elemental Surface Area [4]

Lift and drag coefficients are dimensionless quantities defined as,

$$
\begin{aligned}
C_{D} & =\frac{\text { drag force }}{\text { dynamicpressure } \times \text { area }}=\frac{F_{D}}{\frac{1}{2} \rho U^{2} A} \\
C_{L} & =\frac{\text { lift force }}{\text { dynamicpressure } \times \text { area }}=\frac{F_{L}}{\frac{1}{2} \rho U^{2} A}
\end{aligned}
$$

where $\rho U^{2} / 2$ is the dynamic pressure. The coefficients $C_{D}$ and $\mathrm{C}_{\mathrm{L}}$ strongly depend on the geometry of the object, and hence are usually determined by experiment or numerical simulation. The coefficient of pressure can be examined from the pressure distribution on upper and lower surface.

$C_{P}=\frac{\mathrm{P}-\mathrm{P}_{\infty}}{\frac{1}{2} \rho U_{\infty}{ }^{2}}$

When the distribution of pressure is known, the net forces perpendicular and parallel to the air flow such as lift and drag forces. [6]

\subsection{Curved Blade Airfoil Model}

This model simulates the flow around an inclined curved airfoil using the SST turbulence model. The SST model combines the near-wall capabilities of the $k-\varepsilon$ model with the superior free-stream behavior of the $k$ - $\omega$ model to enable accurate simulations of a wide variety of internal and external flow problems. The model is considered with the flow relative to a reference frame fixed on a curved airfoil. The chord length of the blade is $0.32 \mathrm{~m}$. The temperature of the ambient air is $20^{\circ} \mathrm{C}$ and the relative free stream velocity is $5 \mathrm{~m} / \mathrm{s}$ resulting in a Mach number of 0.15 . The Reynolds number based on the chord length is roughly $1.3 \times 10^{6}$, so the airfoil can be assumed that the boundary layers are turbulent over practically the entire airfoil. The airfoil is inclined at an angle $\alpha$ to the oncoming stream. The geometry is created by using COMSOL's geometry tools.

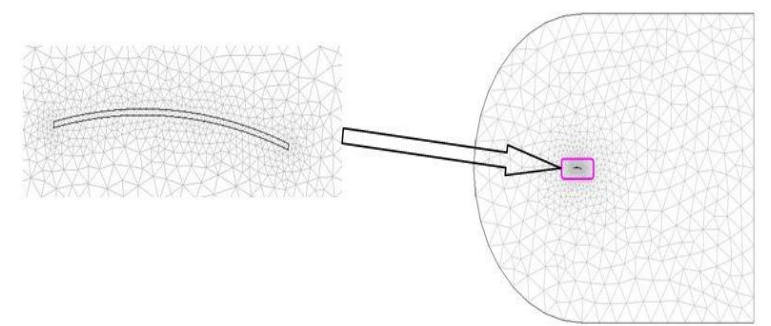

Figure 4. The Computational Mesh of the Circular Arc Airfoil [Simulation]

Meshing was performed in COMSOL Meshing by using free triangular mesh. The elements near the surfaces of airfoil were finer than that of the inlet and outlet boundaries. The computational mesh of the circular arc airfoil model is shown in Figure 4.Meshes were kept to maximum element size of $0.366 \mathrm{~m}$ and minimum element size of $0.0162 \mathrm{~m}$. Inflation layers were implemented on all solid surfaces with a maximum growth rate of 1.15 .

\section{NUMERICAL SIMULATION RESULTS}

Simulations for various angles of attack were done in order to compare the results of different airfoils and then the optimum airfoil was chosen. For these reasons, the models were solved with a range of different angles of attack from 0 to $8^{\circ}$. The pressure and velocity contours with the plots are shown for various angles of attack. The pressure coefficients of different airfoils are also shown as the curves. The lift and the drag coefficients of different airfoils and their ratios are plotted for various angles of attack. The simulation outcomes of pressure distribution of different airfoils at $4^{\circ}$ angle of attack are shown in Figure 6. The pressure on the lower surface of the airfoil was greater than that of the incoming flow stream and as a result it effectively pushed the airfoil upward, normal to the incoming flow stream. At higher angle of attack, the pressure distribution is more obvious and the pressure difference is higher between the surfaces of the airfoils.

Velocity fields at angles of attack $4^{\circ}$ are also shown in Figure 5. The trailing edge stagnation point moved slightly forward on the airfoil at low angles of attack. A stagnation point is a point in a flow field where the local velocity of the fluid is zero. The upper surface of the airfoil experienced a higher velocity compared to the lower surface. That was expected from the pressure distribution. As the angle of attack increased the upper surface velocity was much higher than the velocity of the lower surface. 
International Journal of Science and Engineering Applications

Volume 7-Issue 09,307-312, 2018, ISSN:-2319-7560

Velocity magnitude $(\mathrm{m} / \mathrm{s})$ of NACA $63-215$ airfoil at angle of attack 4 degree

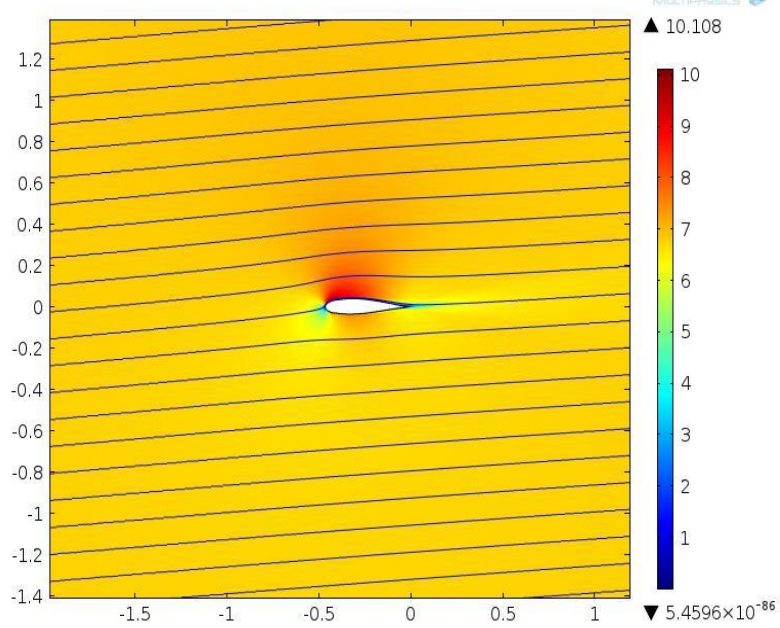

Velocity magnitude ( $\mathrm{m} / \mathrm{s})$ of NACA 64-215 at apha 4 degre

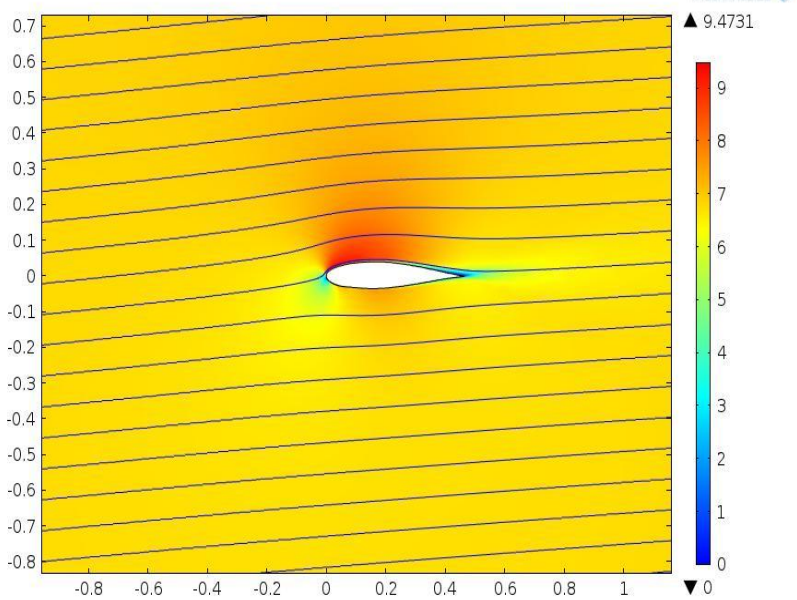

Velocity magnitude $(\mathrm{m} / \mathrm{s})$ of Curved shape airfoil at alpha 4 degree

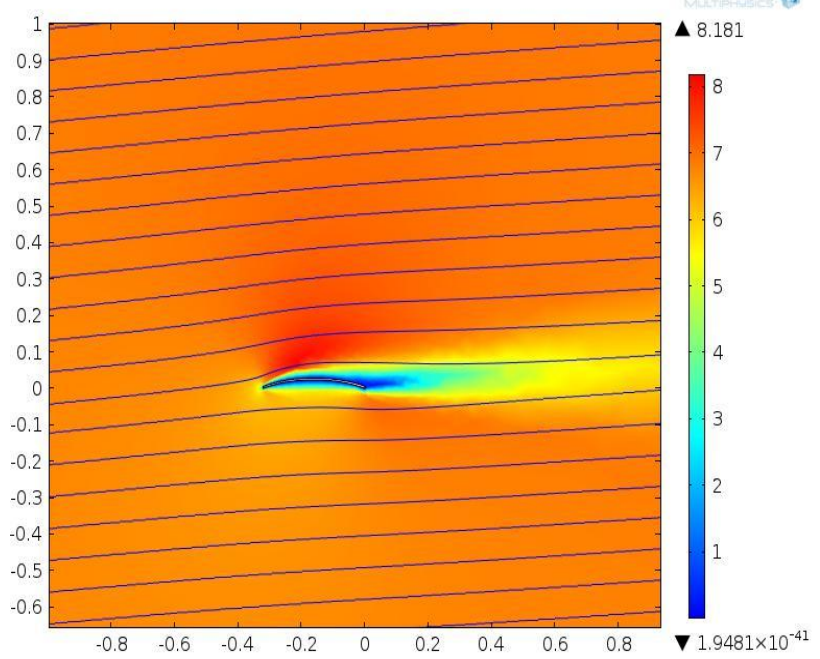

Figure 5. Velocity Magnitude of NACA 63-215, 64-215 and Curved blade at Angles of Attack $4^{\circ}$

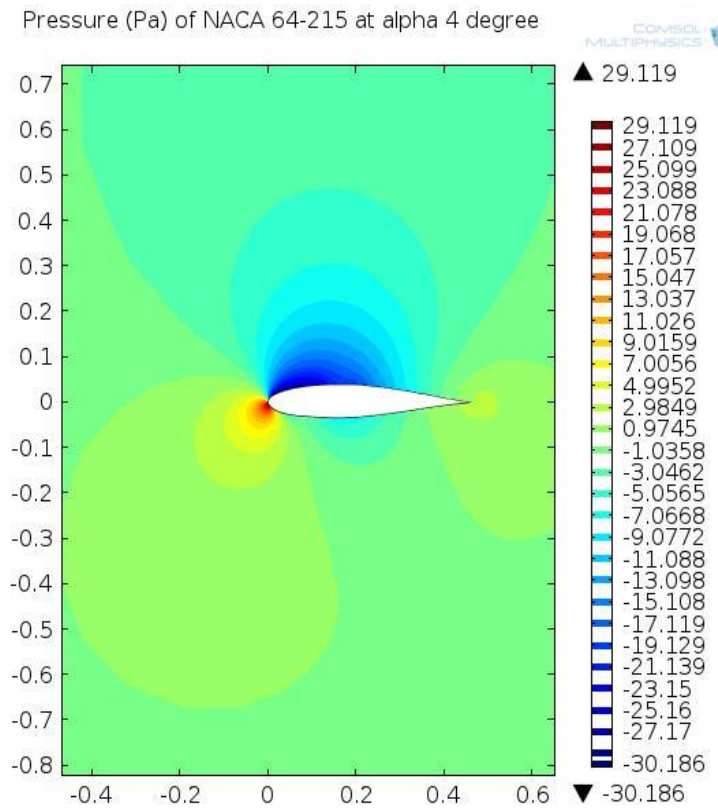

Pressure $(\mathrm{Pa})$ of NACA 63-215 at angle of attack 4 degree
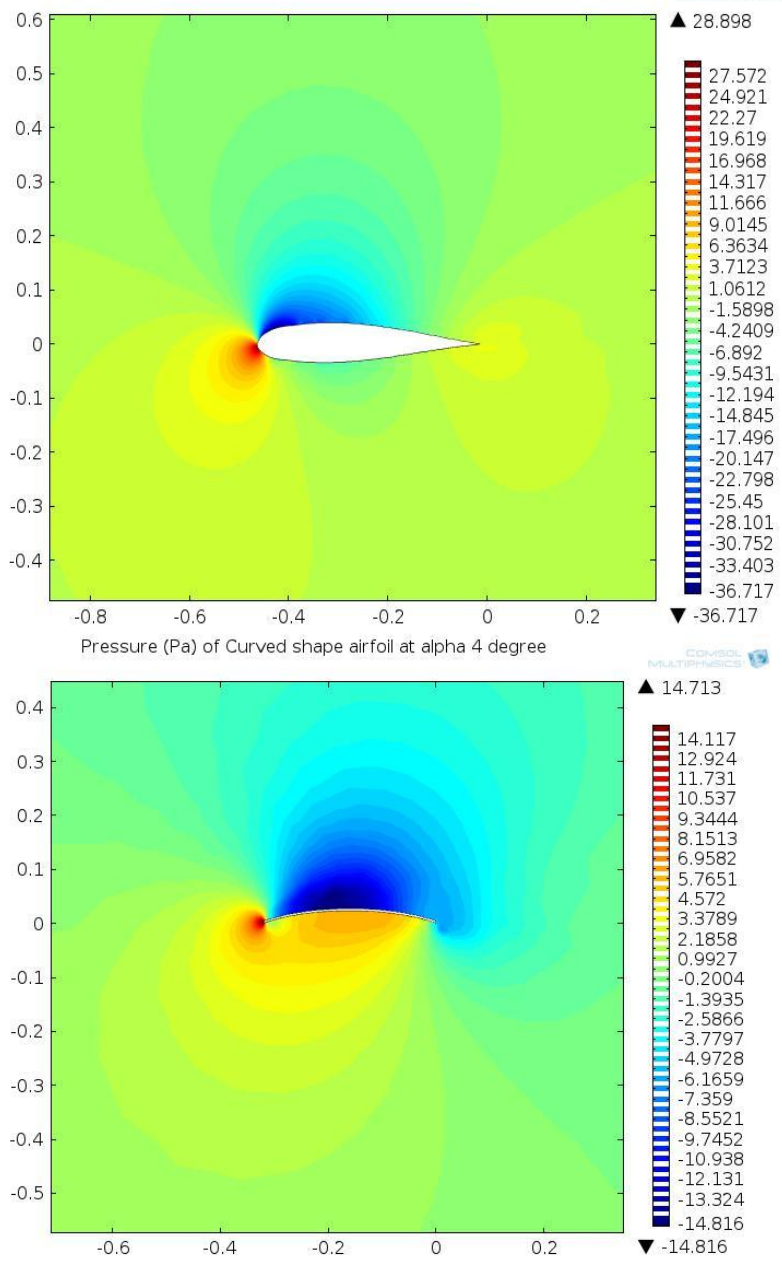

Figure 6. Pressure Distribution of NACA 63-215, 64-215 and curved blade at Angles of Attack $4^{\circ}$ 
The coefficient of pressure, $C_{P}$ curves shows that the pressure on the lower surface was greater than that on the upper surface. The aerodynamics of circular arc airfoil is different from conventional profiles, where the pressure is positive on the lower surface except the trailing edge. Figure 7 shows the pressure coefficients of different airfoils at angle of attack from $4^{\circ}$. It is observed that the pressure coefficients mainly depend on angle of attack.
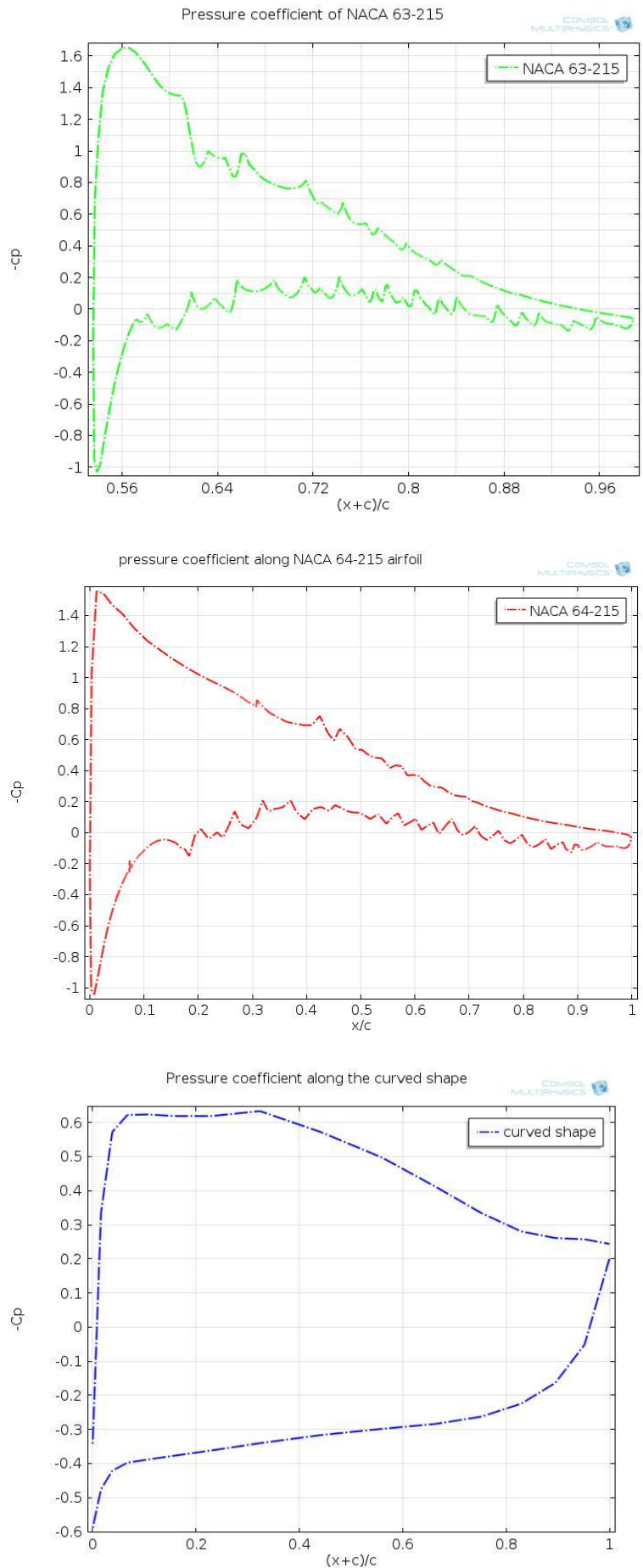

Figure 7. Pressure coefficients of Different Airfoils
The variation of lift coefficients with angle of attack in the range of 0 to $8^{\circ}$ for different airfoils is shown in the Figure 8 . In this paper, NACA 63-215 and NACA 64-215 are utilized to compare the performance of airfoil for windmill rotor. As the angle of attack increases, the lift coefficient increases linearly. Since the effect of flow separation becomes dominant at higher angle of attack, the slope of the curve begins to fall off. Eventually the lift coefficient reaches a maximum value and then begins to decrease. According to the figure, it can be seen that curved shape has higher lift coefficients than NACA airfoils with angle of attack in the range of 0 to $8^{\circ}$.

Figure 9 shows the drag coefficients of different airfoils at various angles of attack. When the angles of attack increase, the drag coefficients of NACA airfoils are also higher. The drag coefficients gradually increase with respect to the angle of attack. NACA 64-215 has higher drag coefficient than that of NACA 63-215. However, the curved shape has a different trend. The drag coefficients of curved shape decrease slightly between angles of attack $0^{\circ}$ and $4^{\circ}$ and then gradually increase after angle of attack $4^{\circ}$. According to the Figure 5.14, the curved shape has smaller drag coefficients after angle of attack $3^{\circ}$.

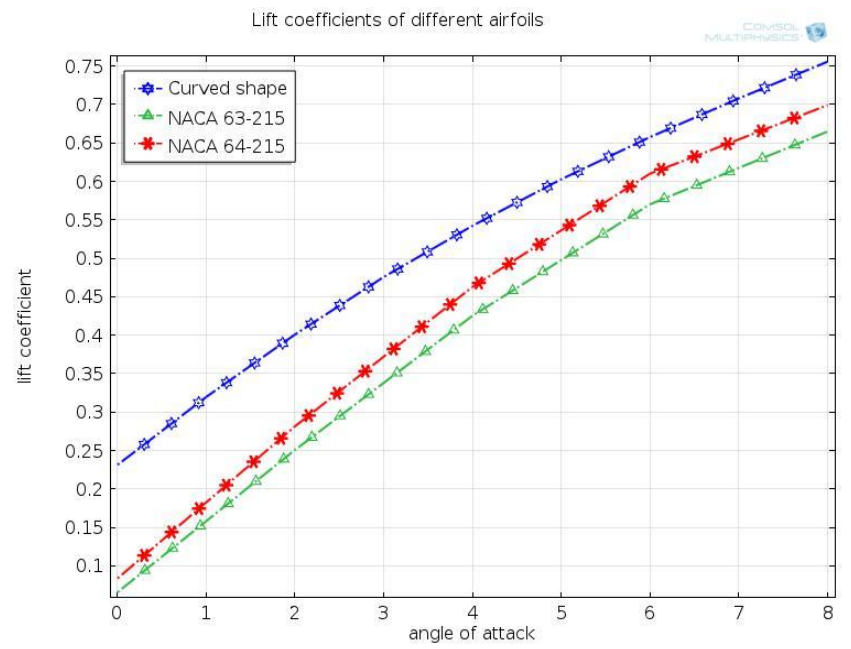

Figure 8. Lift coefficients of Different Airfoils

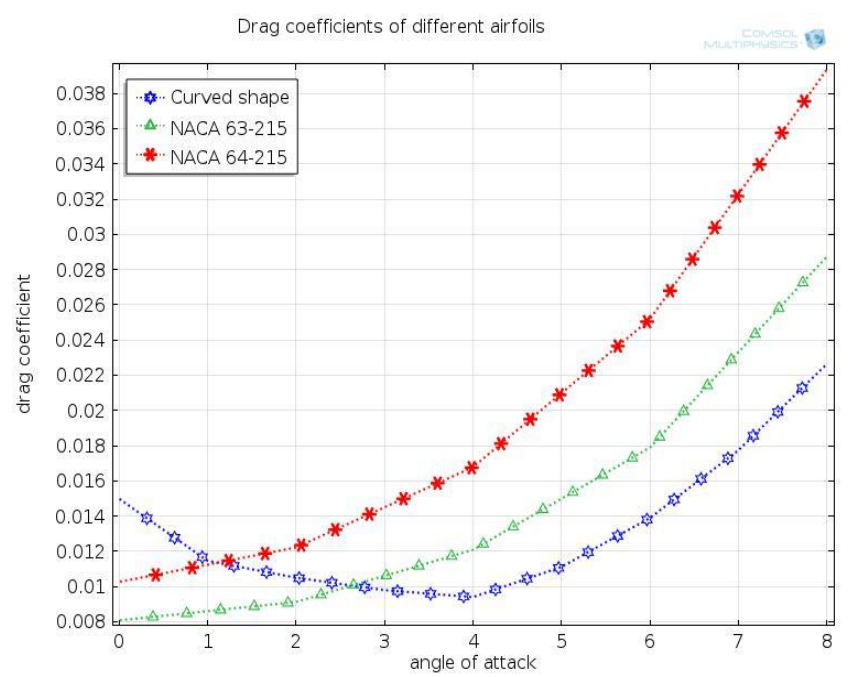

Figure 9. Drag coefficients of Different Airfoils 


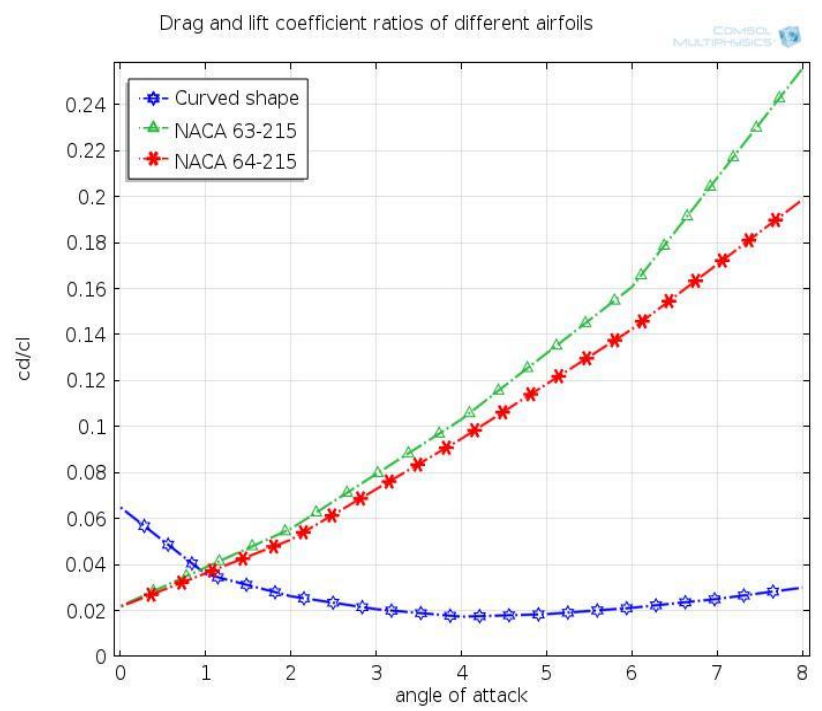

Figure 10. Drag and Lift coefficient ratios of Different Airfoils

The comparison of drag and lift coefficient ratios of different airfoils are illustrated in Figure 10. The slope of NACA 64215 is linearly inclined with respect to higher angles of attack. NACA 63-215 has nearly the same trend of NACA 64-215 and it has higher drag and lift ratio than that of NACA 64215. For the curved shape, the slope is gradually declined from 0 to $4^{\circ}$ of angle of attack and then slightly inclined between $4^{\circ}$ and $8^{\circ}$ of angle of attack. By comparing the drag and lift coefficient ratios of three airfoils, the minimum ratio occurs at the curve shape with angle of attack $4^{\circ}$. This result is good agreement with the assumption data in theoretical design calculation. It can be proved that curved shape is the most suitable airfoil for water pumping windmill.

\section{CONCLUSION}

Wind energy conversion systems are an effective, environmentally friendly power source for household and other applications. With the increasing energy prices and growing energy consumption, many developing countries face the energy problems. In design consideration, the lift and drag coefficients of the blade has been one of the most careful works. For these results, wind tunnel experiments must be required. However, this method is very expensive and facilities are not yet possible for Myanmar to reach this step practically. So CFD software has to be used for this purpose. COMSOL Multiphysics has been selected because it is one of the most powerful tools for CFD problems. In this study, COMSOL Multiphysics $4.3 \mathrm{~b}$ version has been used. In order to do research and select the most suitable airfoil shape for the rotor of windmill water pumping system, the different airfoils were simulated and the results are compared. The curved shape airfoil has the minimum ratio of drag and lift coefficients at angle of attack $4^{\circ}$. In order to get the maximum lift force, the maximum pressure difference from upper and lower section of blade airfoil must be chosen. As the results of simulations, the curved shape airfoil has maximum lift at the corresponding angle of attack.

\section{ACKNOWLEDGMENTS}

First of all, the author is grateful to Dr. Theingi, Rector of Technological University (Thanlyin), for giving the permission to submit the paper.

The author would like to thank his supervisor, Dr. Thwe Thwe Htay, Professor and Head of Mechanical Engineering Department, Technological University (Thanlyin), for her close supervisions and words of inspiration that have always been a motivation to me during the paper work.

The author wishes to express his heartfelt thanks to each and every one who assisted in completing this paper.

Finally, the author deep gratitude and appreciation go to his parents for his moral supports, patience, understanding and encouragement.

\section{REFERENCES}

[1] Lysen E. H, "Introduction to Wind Energy" $2^{\text {nd }}$ Edition, Consultancy Sercices Wind Energy Developing Countries, 1983

[2] Peter Franenkel, "Water-pumping Devices" A handbook for users and choosers, $2^{\text {nd }}$ Edition, Intermediate Technology Publications, 1997.

[3] IRA H. Abbott and Albert E. Van Doenhoff. 1959. "Theory of Wing Sections. Including a Summary of Airfoil Data" Dover Publications, Inc. New York, 1959.

[4] Mr. Vaibhav R. Pannase et al. "Design and Analysis of Windmill" International Journal of Engineering Science and Technology (IJEST), 2013.

[5] Website:http://www.Windworkers.com.htm,Windpowr@ netins.net

[6] Drummond Hislop. "Energy Options. An Introduction to Small-Scale Renewable Energy Technologies" Intermediate Technology Publications, 1992.

[7] Addison, H. The pump users handbook. London, UK, Pitman \& Sons, 1958.

[8] Castro, W.E., Zielinski, P.B., Sandifer, P.B., Performance characteristics of wind pumps, World Mariculture Society Meeting, 6: 451-460, 1975.

[9] Ivens, E. M., (1984), Pumping by windmill, John Wiley and Sons, Inc., New York, 1984.

[10] Petel Frankel, Roy Barlow. Farnces Crick, Anthony Derrick and Various Bokalders. "Windpumps. A Guide for Development Workers"' Intermediate Technology Publications in Association with the Stockholm Environment Institute, 1993. 